\section{Plasma fibrinogen as cardiovascular risk factor}

Dear Sir,

The most striking information missing from two recently published studies $[1,2]$ on body shape in relation to cardiovascular risk is plasma fibrinogen concentration because it is a powerful independent risk factor, possibly stronger than plasma cholesterol [3]. The PROCAM study [2] suggests that if fibrinogen is not elevated there may be no need to treat raised cholesterol [4]. Furthermore, although an independent risk factor, raised fibrinogen is associated with obesity, skin fold thickness, weight/height ratio, lack of exercise, serum triglycerides, serum cholesterol, male sex and diabetes [3]. Smoking and infection raise fibrinogen probably through tissue damage [3]. The present studies are consistent with three large Nordic studies [5-7]. Prospective studies on 24,500 Norwegian women and a smaller number of Swedish women followed for up to 20 years have confirmed that the localisation of adipose tissue is more important than obesity per se and identified non-fasting triglycerides as a risk factor in women but not men. In Chaturvedi's study [2] the 2-h triglyceride levels, which are probably a good approximation to those in random samples, were less than the fasting levels in women but not in men. PROCAM studied healthy men [4] and as there appear to be differences between the sexes with regards to lipid profile risk, a knowledge of the plasma fibrinogen concentration

Corresponding author: Dr. L. Breimer, Department of Chemical Pathology and Human Metabolism, Royal Free Hospital School of Medicine (University of London), London NW3 2QG, UK would have allowed more detailed assessment of the contribution of body shape to cardiovascular risk,

Yours sincerely,

L. Breimer

\section{References}

1. Lemieux S, Després J, Moorjani S et al. (1994) Are gender differences in cardiovascular disease risk factors explained by the level of visceral adipose tissue? Diabetologia 37: $757-764$

2. Chaturvedi N, McKeigue P, Marmot M (1994) Relationship of glucose intolerance to coronary risk in Afro-Caribbeans compared with Europeans. Diabetologia 37: 765-772

3. Ernst E (1990) Plasma fibrinogen - an independent cardiovascular risk factor. J Int Med 227: 365-372

4. Heinrich J, Balleisen F, Schulte H, Assmann G, van de Loo J (1994) Fibrinogen and factor VII in the prediction of coronary risk. Results from the PROCAM study in healthy men. Arteriosclerosis Thrombosis 14: 54-59

5. Stensvold I, Tverdahl A, Urdal P, Graff-Iversen S (1993) Non-fasting serum triglyceride concentration and mortality from coronary heart disease and any cause in middleaged Norwegian women. BMJ 307: 1318-1322

6. Bengtsson, Björkelund C, Lapidus L, Lissner L (1993) Association of serum lipid concentration and obesity with mortality in women: 20 year follow-up of participants in a prospective population study in Gothenburg, Sweden. BMJ 307: $1385-1388$

7. Lindenstrøm E, Boysen G, Nyboe J (1994) Influence of total cholesterol, HDL-cholesterol and triglycerides on cardiovascular risk: the Copenhagen city heart study. BMJ 309: $11-15$

\section{Response from the authors}

\section{Dear Sir,}

We agree that clotting factors, and in particular fibrinogen, may be important predictors of cardiovascular disease within populations, but evidence showing that such factors account for cardiovascular risk differences between populations is less clear.

Several studies in Africa and the United States have shown that people of black African descent have higher fibrinolytic activity compared with whites [1-5]. In the UK, Meade and colleagues [6] showed that factor VII and platelet counts were higher in white compared with black men, but factor VIII was substantially lower [6]. There was a suggestion that factor $\mathrm{V}$ was higher in white men, and that fibrinolytic activity was lower, but none of these comparisons reached statistical significance. However, there were no ethnic differences in fibrinogen levels, and all relationships were much weaker for women. The Whitehall study also found no black-white differences in fibrinogen levels [7]. It is unlikely that such modest differences in clotting factors could account for a halving in coronary heart disease risk in black compared with white men.

Corresponding author: Dr. N. Chaturvedi, Department of Epidemiology and Public Health, University College and Middlesex School of Medicine, 66-72 Gower Street, London, WC1E 6EA, UK
Calculation of standardised regression effects for factor VII (where the ethnic difference was largest and in the "right" direction), showed that even a one standard deviation difference in factor VII could result in only a $37 \%$ increase in coronary risk over the next 5 years [8]. The ethnic difference observed was however only half a standard deviation. Furthermore, the favourable effects of factor VII may be offset by the higher factor VIII concentration observed in blacks compared to whites. These findings provide little support for the hypothesis that clotting factors play a major part in explaining ethnic differences in cardiovascular disease risk.

Yours sincerely,

N. Chaturvedi

P.M. McKeigue,

M. G. Marmot

\section{References}

1. Gillman T, Naidoo SS, Hathorn M (1957) Fat, fibrinolysis, and atherosclerosis in Africans. Lancet II: 696-697

2. Franz RC, Kark AE, Hathorn M (1961) Postoperative thrombosis and plasma fibrinolytic activity. A comparative study in Africans, Indians and Whites. Lancet I: 195-197

3. Barr RD, Ouna N, Kendall AG (1973) The blood coagulation and fibrinolytic enzyme systems in healthy adult Africans and Europeans - a comparative study. Scot Med J 18: 93-97 
4. Dischinger P, Tyroler HA, McDonagh R Jr, Hames CG (1980) Blood fibrinolytic activity, social class and habitual physical activity. A study of black and white men in Evans County, Georgia. J Chronic Dis 33: 283-290

5. Meade TW, Stirling Y, Thompson SG et al. (1986) An international and interregional comparison of haemostatic variables in the study of ischaemic heart disease. Report of a working group. Int J Epidemiol 15: 331-336

6. Meade TW, Brozovic M, Chakrabarti R, Haines AP, North WRS, Stirling Y (1978) Ethnic group comparisons of vari- ables associated with ischaemic heart disease. Br Heart $\mathrm{J} 40$ : 789-795

7. Brunner EJ, Marmot MG, White IR et al. (1993) Gender and employment grade differences in blood cholesterol, apolipoproteins and haemostatic factors in the Whitehall II study. Atherosclerosis 102: 195-207

8. Meade TW, Brozovic M, Chakrabarti RR et al. (1986) Haemostatic function and ischaemic heart disease: principal results of the Northwick Park heart study. Lancet II: $533-537$

\section{Reply from the authors}

\begin{abstract}
Dear Sir,
We agree with Dr. Breimer's letter suggesting that the measurement of plasma fibrinogen concentrations would have provided additional information relevant to cardiovascular disease risk in our sample of men and women [1]. As stated by Dr. Breimer, it is well recognized that hypofibrinolysis, due to elevated plasma fibrinogen activator inhibitor 1 (PAI-1) levels is associated with an increased cardiovascular disease risk [2, 3]. In addition, it has been shown that elevated PAI-1 concentrations are observed in obese patients [4]. It has, however, been reported that the association between the waist-to-hip ratio (a crude index of a preferential accumulation of abdominal adipose tissue) and PAI-1 levels was weak and that after adjustment for body mass index, insulin and triglyceride levels, no significant association was found between the waist-to-hip ratio and PAI-1 levels [5]. To the best of our knowledge, the potential association between abdominal visceral adipose tissue and PAI-1 levels is a topic that has received little attention so far.

PAI-1 levels have also been found to be associated with high insulin and triglyceride concentrations [4-6]. Although insulin concentration appears to be the best independent correlate of PAI-1 levels, plasma triglyceride concentrations have been reported to remain significantly associated with PAI-1 levels after controls for body mass index, waist-to-hip ratio and insulin [5]. These results therefore suggest that fibrinolytic activity may be associated with some metabolic alterations related to the insulin-resistant-hyperinsulinaemic state and that it might possibly represent another component of the well-known cluster of metabolic alterations, the so-called insulin-resistance syndrome, which results in an increased cardiovascular disease risk $[7,8]$.

The main finding of our study was that the sexual dimorphism observed for abdominal visceral adipose tissue accumulation was a strong correlate of the gender difference in several cardiovascular disease risk factors. Indeed, an adjustment for abdominal visceral adipose tissue area eliminated most of the gender differences initially found in the cardiovascular disease risk profile. The issue of sex differences in fibrinolysis activity may be considered as controversial as Ernst [9] reported higher fibrinogen concentrations in men than in women whereas Vague et al. [4] did not find any significant difference among men and women for PAI-1 levels. Differences in subjects' characteristics may contribute to explain discrepancies
\end{abstract}

Corresponding author: Dr. J.-P.Després, Lipid Research Center, CHUL, 2705 Laurier Blvd, Ste-Foy, Québec, Canada, G1V 4G2 among these studies. Although the point raised by Dr. Breimer is relevant, the objective of our study was not to test for potential differences in fibrinogen or PAI-1 levels among our men and our premenopausal women, nor to study the association between visceral adipose tissue and variables related to fibrinolytic activity. This interesting issue will be the subject of some of our future investigations.

Finally we want to thank Dr. Breimer for his interest in our work as we fully agree with the notion that an altered fibrinolytic system is likely to represent another component of the cluster of metabolic aberrations increasing cardiovascular disease risk among individuals with excess visceral adipose tissue accumulation.

Yours sincerely,

J.-P.Després and S. Lemieux

\section{References}

1. Lemieux S, Després J-P, Moorjani S et al. (1994) Are gender differences in cardiovascular disease risk factors explained by the level of visceral adipose tissue? Diabetologia 37: $757-764$

2. Francis RB, Kawanishi D, Baruch T, Mahrer P, Rahimtoola S, Feinstein DI (1988) Impaired fibrinolysis in coronary artery disease. Am Heart J 115: 776-780

3. Olofsson BO, Dahlen G, Nilsson TK (1989) Evidence for increased levels of plasminogen activator inhibitor and tissue plasminogen activator in plasma of patients with angiographically verified coronary artery disease. Eur Heart J 10: $77-82$

4. Vague P, Juhan-Vague I, Aillaud MF et al. (1986) Correlation between blood fibrinolytic activity, plasminogen activator inhibitor level, plasma insulin level, and relative body weight in normal and obese subjects. Metabolism 35: 250253

5. Vague P, Juhan-Vague I, Chabert V, Alessi MC, Atlan C (1989) Fat distribution and plasminogen activator inhibitor activity in non-diabetic obese women. Metabolism 38: $913-$ 915

6. Juhan-Vage I, Alessi MC, Vague P (1991) Increased plasma plasminogen activator inhibitor 1 levels. A possible link between insulin resistance and atherothrombosis. Diabetologia 34: $457-462$

7. Reaven GM (1988) Role of insulin resistance in human disease. Diabetes 37: 1595-1607

8. DeFronzo RA, Ferrannini E (1991) Multifaceted syndrome response for NIDDM, obesity, hypertension, dyslipidemia, and atherosclerotic cardiovascular disease. Diabetes Care 14: 173-194

9. Ernst E et al. (1990) Plasma fibrinogen - an independent cardiovascular risk factor. J Int Med 227: 365-372 